\title{
Knowledge Assessment of Symptoms Identification of Acute Heart Attack among Staff and Students of Universiti Sains Malaysia
}

\author{
Omar Yahya Ahmed Al-shargi ${ }^{1,2,}{ }^{*}$ Sultan Ayesh Mohammed Saghir ${ }^{3 *}$, Nader Al-balagi ${ }^{4}$, Amer Hayat $^{1}$, Wesam al-Amarat ${ }^{5}$, \\ and Abdullah Saleh Al-Wajeeh ${ }^{6}$ \\ ${ }^{1}$ Department of Pharmacology, College of Pharmacy, Riyadh Elm University, Riyadh, Saudi Arabia; Omar. \\ 2Department of Clinical Pharmacy, School of Pharmaceutical Sciences, Universiti Sains Malaysia, Penang, Malaysia. \\ ${ }^{3}$ Department of Medical Analysis, Princess Aisha Bint Al-Hussein College of Nursing and Medical Sciences, Al-Hussein Bin Talal \\ University, Ma`an, Jordan, 71111. \\ ${ }^{4}$ Kingdom of Saudi Arabia, Riyadh, Ministry of Health, Saudi Arabia. \\ 5Department of Medical Support, Al-karak University College, Al-Balqa' Applied University, Jordan. \\ ${ }^{6}$ Anti-DopingLabQatar, Doha, Qatar.
}

*Corresponding author's E-mail: oma12361236@gmail.com

Received: 14-08-2019; Revised: 16-11-2020; Accepted: 22-11-2020; Published on: 15-12-2020.

\section{ABSTRACT}

This study aimed to assess the knowledge of acute heart attack symptoms among staff and students at Universiti Sains Malaysia (USM) community. This is a cross-sectional study conducted from November 2016 to May 2017 in USM community. In this study, 520 volunteers were participated. The participants included academics, non-academics, and students using a self-administered validated questionnaire. Out of the 520 distributed questionnaires, only 490 responded, with a response rate of $94.23 \%$. After clean-up, 25 questionnaires were excluded and $465(94.89 \%)$ questionnaires were used for final data analysis. The distribution of participants was 200 (undergraduate students), 94 (postgraduate students), 80 (academics), and 91 (non-academics). The average level of awareness of symptoms of acute heart attack ranged from $43.9-84.9 \%$. The results showed that calling an ambulance was recommended by $22.2 \%$ of participants, $89.7 \%$ knew $\geq 1$ symptom, and $6.20 \%$ knew all five symptoms for acute heart attack. Just 7 people out of 465 $(1.50 \%)$ had excellent knowledge. The awareness of acute heart attack symptoms and the suitable action to take at the onset of symptoms among USM community was poor. The current study demonstrated that promotional and educational strategies to increase the overall awareness about heart attack are of paramount importance.

Keywords: Ischaemic heart diseases, Acute heart attack, Awareness, Knowledge.

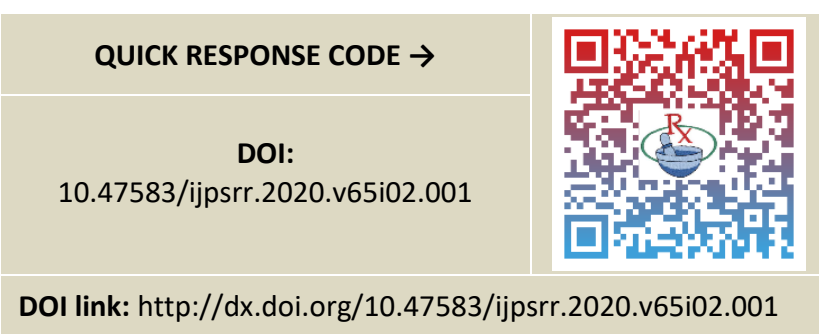

\section{INTRODUCTION}

schaemic heart disease (IHD) is the most common cause of mortality in the world, with an estimated 7.4 million deaths reported in $2012^{1}$. In Malaysia, IHD accounted for the highest number of deaths, with an estimated 98.9 deaths per 100,000 populations ( $20.1 \%$ of all deaths $)^{1,2}$. Heart attack, also known as acute myocardial infarction (AMI) occurs when there is inadequate blood supply to a part of the heart, causing damage to the heart muscle ${ }^{3}$. Acute heart attack is a time-dependent event in which quick arrival of the patient to the hospital is important for prompt diagnosis and treatment ${ }^{4,5}$. This reduces mortality, improves prognosis, and shortens the length of hospital stay ${ }^{6}$. Published literature shows that the rate of mortality caused by acute heart attack decreased by $1.5 \%$, for every $30 \mathrm{~min}$ of reduction of delay in reperfusion time ${ }^{6}$. Moreover, it has been reported that the mortality rate decreases by $50 \%$ and $23 \%$ when the reperfusion occurs within $1 \mathrm{~h}$ and $3 \mathrm{~h}$, respectively ${ }^{7}$. The delay in reaching the hospital after acute heart attack can be divided into three stages, including patient's decision time (from the onset of symptoms until the decision to seek medical care), time from the decision to first medical contact (FMC), and time from FMC to hospital arrival including the transportation time $e^{8,9}$.

Understanding and interpretation of the symptoms of AMI greatly influences the type of response and the decision on whether immediate action is necessary. Lack of knowledge about symptoms of acute heart attack has been known to be associated with longer patient delay ${ }^{10,}{ }^{11}$. Previous studies have reported that socio-demographic, clinical, cognitive, psychological, behavioural, and contextual factors influence patient delay, and are crucial for understanding the phenomenon of delay ${ }^{12}$. In addition, older age, female sex and comorbidities have been found to be associated with prolonged delays ${ }^{13-15}$. There is no published study from Malaysia that has investigated the awareness about heart attack symptoms and the first response following the onset of symptoms, among the general public or in specific population groups. Personal clinical experience in the cardiology ward shows that many patients present at the hospital to seek medical 
intervention very late after the onset of symptoms. However, there is no evidence to the reason for coming late to hospitals. Misinterpretation of symptoms or not considering them critical enough might be the main reasons for delayed admission to the hospital. Consequently, the current study was designed to understand the knowledge about symptoms of heart attack and the response to these among the Universiti Sains Malaysia (USM) community. This will serve as an exploratory study for the larger community of the university, since this community is expected to be more informed compared to the general population.

\section{METHODS}

\section{Ethics approval}

The permission to conduct the study was obtained from the Joint Ethics Committee of school of pharmaceutical sciences, USM - Hospital Lam Wah Ee on clinical studies [No. USM-HL WE/IEC/2017 (0002)].

\section{Study design and setting/population}

This is a cross-sectional, descriptive study using a selfadministered survey. The study was conducted over a sixmonth period from November 2016 to May 2017. The study was conducted at the main campus of USM (Penang, Malaysia). Based on the data obtained from the Institute of Postgraduate Studies (IPS) and the University Chancellery in 2017, the estimated number of students in the main campus in 2016 was 15,736 . The study population consisted of the staff and students drawn from the following domains: applied sciences, applied arts, pure sciences, and pure arts. The inclusion criteria were being a staff or student of the USM and willing to provide consent to participate in the study, while the exclusion criteria were not being a staff or student of USM. Students were classified into undergraduate and postgraduate groups, while the staff was categorised as either academic or nonacademic staff.

\section{Questionnaire development and validation}

Questionnaire development: Questions included in the questionnaire were generated from a literature review of similar studies and discussion with experts in the field $^{16,17}$.

Questionnaire validation: The quality of the questionnaire was checked by selecting eight target participants from the staff members, and postgraduate and undergraduate students. The participants were asked to review the questionnaire and provide their feedback about content clarity, ease of understanding, and language. The draft questions were revised based on the feedback received from the participants. To ensure content validity, the draft questionnaire was presented to an expert panel comprising five academic staff from the discipline of clinical pharmacy. The panel was asked to review the relevance of questions for inclusion in the final questionnaire, with respect to and representation of the construct being measured. Minor revisions were done based on their suggestions.

Reliability: To ensure consistency and reliability of the questionnaire, a pilot study was conducted among 60 potential participants. The responses received were analysed and the consistency and reliability of the questionnaire was determined using Cronbach's alpha. The obtained result was satisfactory with an alpha value of (0.64). To ensure accuracy of the findings of the main study, participants who participated in the pilot study were excluded from the final analysis.

The final validated questionnaire was then translated into the Malay language by an expert. A forward and backward translation was conducted to ensure the questionnaire was accurately translated. The final questionnaire was thus in two languages (English and Malay).

Format of the questionnaire: The questionnaire was in the form of close-ended questions related to the participants' socio-demographic characteristics like gender, age, marital status, nationality, and race. Other questions included those related to clinical information such as the underlying medical history of the participant or his immediate family members, acquaintances (friend) or neighbours, previous knowledge about acute heart attack (whether the participant has heard of heart attack). The questionnaire consisted of options like "Yes", "No" and "I don't know" with a 'yes' answer counted as 1 point and a 'no' or 'I don't know' answer not receiving any points.

\section{Data collection}

The questionnaire was distributed among the academic and administrative staff. The administrative staff included those from the included schools, hostels and libraries of the USM main campus. The participants were asked to complete the questionnaire after reading the participants' information sheet and consent form.

\section{Sample size calculation}

The minimum sample size to be included in this study was calculated using the finite population proportion formula:

$$
n=\frac{N p(1-p) z^{2} 1-\alpha / 2}{d^{2}(N-1)+p(1-p) z^{2} 1-\alpha / 2}
$$

Where $\mathrm{N}=$ population size

\section{$\mathrm{P}=$ proportion of participants aware of AHA symptoms}

The population size of the target participants was estimated to be 30,000 and since there has been no previous study about the awareness of AHA symptoms among the target population, a proportion of $50 \%$ was assumed. Assuming the level of significance of 0.05 , and precision of 0.05 a sample size of 380 was determined. To factor in for non-response or unreturned questionnaires, $20 \%$ of the calculated sample size was added. The total estimated sample size calculated was therefore 456 participants. 


\section{Statistical analysis}

The data were analysed using IBM SPSS Statistics for Windows version 20 (IBM Corp., Armonk, NY, USA). Descriptive data were analysed using descriptive statistics. Numerical data were presented as mean and standard deviation, while the categorical variables were presented as frequency and percentage. The differences between the categorical variables were compared using appropriate Chi-squared tests. Multiple logistic regression analysis was performed to determine the factors associated with knowledge of identification of AHA symptoms among the USM community. Univariable analysis was conducted to determine the potential variables for multivariable analysis. Variable selection was done using forward selection.

\section{RESULTS}

Out of the 520 questionnaires distributed, 490 were retrieved, making a response rate of $94.23 \%$. Twenty-five questionnaires were excluded from the study which included participants not belonging to the main campus and/or incomplete questionnaires. After data cleanup, 465 out of 490 questionnaires were used for final data analysis, thus a usable data rate of $94.89 \%$. Among the participants, undergraduate students were 200 , postgraduate students 94, academicians 80, and non-academicians 91. Participants from schools of applied sciences had the highest number $143,(30.80 \%)$, followed by pure sciences $123(26.50 \%)$ then applied arts and pure arts with 122 (26.20\%) and 77 (16.61\%) participants respectively. The majority of the respondents were within age group 18-29 years old (44.9\%). The youngest participants were 19 years old while the oldest were 65 years old. The respondents were 254 (54.6\%) female and 211 (45.4\%) male. Most of the respondents were from Malay ethnicity 257 (55.3\%). The frequency of participants according to their demographics and other characteristics are illustrated in the supplementary files.

\section{Awareness of symptoms of acute heart attack}

Table 1 illustrates the responses regarding the awareness of every single symptom of acute heart attack and the appropriate response at the onset of symptoms. The proportion of subjects who were aware of major symptoms of acute heart attack was highest for "having pain or discomfort in the chest" $(84.9 \%)$, followed by "difficulty in breathing" (79.4\%); "sudden weakness or dizziness" (54.6\%); "Sudden pain or discomfort in the arms or shoulders" (45.2\%); and "Sudden pain or discomfort in the jaw, neck, or back" (43.9\%). Of all respondents, $22.2 \%$ stated that they would call an ambulance if anyone has symptoms of acute heart attack while most respondents $(49.90 \%)$ reported taking the patient to the hospital is the most appropriate option. From the participants, 1.5\% reported that they do not know what they should do first.

\section{Knowledge assessment of AHA symptom identification}

Data for evaluation of knowledge based on identifying of each individual symptom are presented in Table 1. Females were significantly more knowledgeable in just two symptoms; "pain or discomfort in the chest" $(89.40 \% \mathrm{Vs}$. $79.60 \%, p=0.001)$ and "shortness of breathing" (83.90\% Vs. $73.90 \%, p=0.01)$. Also, younger people were more knowledgeable in "pain or discomfort in the chest" $(p=0.01)$ and in the "importance of calling an ambulance" $(p=0.04)$ but non-married were more knowledgeable than married in "pain or discomfort in the jaw, neck or back" (48.70\% Vs. 39.40\%, $p=0.05)$ and "pain and discomfort in the chest" $(89.70 \%$ Vs. $80.50 \%, p=0.01)$. "Pain or discomfort in the arms or shoulders" significantly was more identified by international students than locals $(p=0.001)$ while there were no other differences in the rest of evaluation tools in terms of nationality and race (Table 1).

Table 1: Awareness of each individual symptom of acute heart attack and calling an ambulance based on demographics, pre-existing condition, current position, school, previous knowledge and history of heart attack

\begin{tabular}{|c|c|c|c|c|c|c|c|c|}
\hline \multicolumn{9}{|c|}{ Percentage of recognising individual symptoms and response (\%) } \\
\hline \multicolumn{2}{|l|}{ Characteristics } & $\begin{array}{c}\text { Pain or discomfort } \\
\text { in the jaw, neck, or } \\
\text { back }\end{array}$ & $\begin{array}{l}\text { Weakness } \\
\text { or dizziness }\end{array}$ & $\begin{array}{c}\text { Pain or } \\
\text { discomfort } \\
\text { in the chest }\end{array}$ & $\begin{array}{l}\text { Blurred } \\
\text { vision } \\
\text { (trap } \\
\text { question) }\end{array}$ & $\begin{array}{c}\text { Pain or } \\
\text { discomfort } \\
\text { in the arms } \\
\text { or } \\
\text { shoulders }\end{array}$ & $\begin{array}{l}\text { Shortness } \\
\text { of breath }\end{array}$ & $\begin{array}{l}\text { Calling an } \\
\text { Ambulance }\end{array}$ \\
\hline \multicolumn{2}{|l|}{ Total } & 43.9 & 54.6 & 84.9 & 63.9 & 45.2 & 79.4 & 22.2 \\
\hline \multirow{3}{*}{ Gender } & Male & 41.20 & 53.60 & 79.60 & 62.10 & 45.50 & 73.90 & 21.30 \\
\hline & Female & 46.10 & 55.50 & 89.40 & 65.40 & 44.90 & 83.90 & 22.80 \\
\hline & $P$ value & 0.30 & 0.67 & 0.003 & 0.50 & 0.89 & 0.008 & 0.70 \\
\hline \multirow{4}{*}{ Age group, years } & $18-29$ & 44.00 & 57.10 & 91.20 & 63.20 & 41.20 & 82.40 & 26.90 \\
\hline & $30-40$ & 41.90 & 53.40 & 81.20 & 63.80 & 45.00 & 79.10 & 16.20 \\
\hline & $>40$ & 47.80 & 52.20 & 80.40 & 65.30 & 53.30 & 73.90 & 25.00 \\
\hline & $P$ value & 0.64 & 0.67 & 0.01 & 0.95 & 0.17 & 0.26 & 0.04 \\
\hline \multirow{2}{*}{ Marital Status } & Not married & 48.70 & 58.90 & 89.70 & 61.60 & 43.80 & 83.00 & 24.60 \\
\hline & Married & 39.40 & 50.60 & 80.50 & 66.00 & 46.50 & 75.90 & 19.90 \\
\hline
\end{tabular}




\begin{tabular}{|c|c|c|c|c|c|c|c|c|}
\hline & $P$ value & 0.045 & 0.07 & 0.005 & 0.33 & 0.56 & 0.06 & 0.23 \\
\hline \multirow{6}{*}{ Nationality/Race } & Malay & 38.90 & 50.20 & 84.80 & 67.70 & 40.10 & 80.20 & 20.60 \\
\hline & Chinese & 53.20 & 57.10 & 84.40 & 58.50 & 36.40 & 74.00 & 29.90 \\
\hline & Indian & 52.30 & 54.50 & 90.90 & 65.90 & 65.90 & 84.10 & 13.60 \\
\hline & Other_malaysian & 50.00 & 69.20 & 80.80 & 53.80 & 46.20 & 76.90 & 25.00 \\
\hline & International & 40.00 & 60.00 & 85.70 & 60.00 & 74.30 & 82.90 & 22.90 \\
\hline & $P$ value & 0.11 & 0.13 & 0.74 & 0.27 & 0.001 & 0.65 & 0.28 \\
\hline \multirow{11}{*}{ Comorbidity } & Yes & 48.80 & 51.20 & 72.10 & 69.80 & 39.50 & 67.40 & 20.90 \\
\hline & No & 43.40 & 55.00 & 86.30 & 63.30 & 45.70 & 80.60 & 22.30 \\
\hline & $P$ value & 0.49 & 0.63 & 0.013 & 0.40 & 0.44 & 0.043 & 0.84 \\
\hline & Yes & 50.00 & 58.30 & 83.30 & 58.30 & 41.70 & 83.30 & 29.20 \\
\hline & No & 43.50 & 54.40 & 85.00 & 64.20 & 45.40 & 79.10 & 21.80 \\
\hline & $P$ value & 0.53 & 0.71 & 0.82 & 0.56 & 0.72 & 0.62 & 0.40 \\
\hline & Yes & 59.10 & 56.80 & 88.60 & 68.20 & 47.70 & 86.40 & 15.90 \\
\hline & No & 42.30 & 54.40 & 84.60 & 63.40 & 44.90 & 78.60 & 22.80 \\
\hline & $P$ value & 0.03 & 0.76 & 0.47 & 0.53 & 0.72 & 0.23 & 0.30 \\
\hline & Yes & 62.50 & 56.20 & 81.20 & 62.50 & 50.00 & 75.00 & 18.80 \\
\hline & No & 43.20 & 54.60 & 85.10 & 63.90 & 45.00 & 79.50 & 22.30 \\
\hline CAD & $P$ value & 0.13 & 0.89 & 0.67 & 0.91 & 0.69 & 0.66 & 0.74 \\
\hline \multirow{5}{*}{ Current Position } & Academicians & 53.80 & 58.80 & 85.00 & 60.00 & 61.20 & 81.20 & 26.20 \\
\hline & Non academician & 39.60 & 46.20 & 76.90 & 68.10 & 35.20 & 71.40 & 19.80 \\
\hline & $\begin{array}{l}\text { Undergraduate } \\
\text { student }\end{array}$ & 42.50 & 58.00 & 88.00 & 63.00 & 40.00 & 81.00 & 22.00 \\
\hline & $\begin{array}{l}\text { Postgraduate } \\
\text { student }\end{array}$ & 42.60 & 52.10 & 86.20 & 64.90 & 52.10 & 81.90 & 21.30 \\
\hline & $P$ value & 0.25 & 0.23 & 0.11 & 0.72 & 0.001 & 0.22 & 0.77 \\
\hline \multirow{5}{*}{ School } & Applied arts & 43.40 & 38.50 & 77.00 & 65.60 & 45.10 & 73.00 & 22.10 \\
\hline & Applied sciences & 46.20 & 56.60 & 89.50 & 65.00 & 44.80 & 82.50 & 25.90 \\
\hline & Pure arts & 42.90 & 63.60 & 92.20 & 67.60 & 41.60 & 87.00 & 28.60 \\
\hline & Pure sciences & 42.30 & 62.60 & 82.90 & 58.80 & 48.00 & 77.20 & 13.80 \\
\hline & $P$ value & 0.93 & 0.001 & 0.008 & 0.53 & 0.85 & 0.07 & 0.04 \\
\hline \multirow{3}{*}{$\begin{array}{l}\text { Previous Knowledge } \\
\text { of HA }\end{array}$} & Yes & 44.60 & 55.40 & 86.20 & 63.50 & 45.70 & 80.50 & 22.30 \\
\hline & No & 0.00 & 12.50 & 12.50 & 87.50 & 12.50 & 12.50 & 12.50 \\
\hline & $P$ value & 0.01 & 0.02 & 0.001 & 0.16 & 0.06 & 0.001 & 0.51 \\
\hline \multirow{3}{*}{$\begin{array}{l}\text { Received HA } \\
\text { Information }\end{array}$} & Yes & 46.20 & 56.80 & 86.70 & 61.30 & 45.60 & 80.90 & 20.40 \\
\hline & No & 34.10 & 45.50 & 77.30 & 75.00 & 43.20 & 72.70 & 29.50 \\
\hline & $P$ value & 0.04 & 0.06 & 0.03 & 0.02 & 0.68 & 0.09 & 0.06 \\
\hline \multirow{3}{*}{ Self-history of HA } & Yes & 50.00 & 50.00 & 92.90 & 71.40 & 50.00 & 92.90 & 7.10 \\
\hline & No & 43.70 & 54.80 & 84.70 & 63.60 & 45.00 & 78.90 & 22.60 \\
\hline & $P$ value & 0.64 & 0.72 & 0.40 & 0.55 & 0.71 & 0.21 & 0.17 \\
\hline \multirow{5}{*}{ Indirect History of HA } & $\begin{array}{l}\text { Immediate family } \\
\text { (1) }\end{array}$ & 56.80 & 63.20 & 89.50 & 60.00 & 51.60 & 85.30 & 20.00 \\
\hline & $\begin{array}{l}\text { Relative, friend or } \\
\text { neighbour (2) }\end{array}$ & 42.20 & 53.30 & 84.80 & 63.10 & 41.00 & 81.10 & 22.50 \\
\hline & Both $1 \& 2$ & 41.70 & 50.00 & 91.70 & 66.70 & 75.00 & 75.00 & 0.00 \\
\hline & None & 36.80 & 50.90 & 80.70 & 68.40 & 45.20 & 71.10 & 25.40 \\
\hline & $P$ value & 0.03 & 0.29 & 0.31 & 0.63 & 0.05 & 0.06 & 0.22 \\
\hline
\end{tabular}

$\mathrm{HTN}=$ hypertension, $\mathrm{DM}=$ Diabetes mellites, $\mathrm{CAD}=$ coronary artery disease, $\mathrm{HA}=$ heart attack

For pre-existing conditions, normotensive patients significantly have better knowledge of pain or discomfort in the chest and shortness of breathing than those who are hypertensive $(86.30 \%$ vs $72.10 \%, p=0.01)$ and $80.60 \%$ vs $67.40 \%, p=0.04$ ) respectively), while hyperlipidemic respondents significantly knew pain or discomfort in the jaw, neck, or back more than non-hyperlipidemic (59.10\% Vs. $42.30 \%, p=0.03$ ). Academicians significantly showed to be having higher awareness in the arms or shoulder pain compared with other participants $(p=0.001)$. A significant higher awareness for three symptoms was 
also found in respondents from pure arts schools $(p=0.001)$. People who have heard about heart attack were more aware of four individual symptoms than those who have never heard about the disease, while receiving information related to heart attack showed to make a significant difference in identifying $50 \%$ of symptoms.

Table 2-Awareness of acute heart attack by number of identified symptoms and excellent knowledge

\begin{tabular}{|c|c|c|c|c|c|c|c|c|c|}
\hline \multirow{2}{*}{\multicolumn{3}{|c|}{ Characteristics }} & \multicolumn{7}{|c|}{ Percentage (\%) } \\
\hline & & & $\geq 1$ & $\geq 2$ & $\geq 3$ & $\geq 4$ & 5 & $6^{a}$ & $\begin{array}{c}\text { Excellent } \\
\text { knowledge }^{\text {b }}\end{array}$ \\
\hline \multicolumn{3}{|l|}{ Total } & 89.70 & 84.90 & 69.00 & 43.70 & 20.60 & 6.20 & 1.50 \\
\hline \multirow{3}{*}{\multicolumn{2}{|c|}{ Gender }} & Male & 85.80 & 79.60 & 64.90 & 40.80 & 22.70 & 5.70 & 0.90 \\
\hline & & Female & 92.90 & 89.40 & 72.40 & 46.10 & 18.90 & 6.70 & 2.00 \\
\hline & & $P$ value & 0.01 & 0.003 & 0.08 & 0.25 & 0.31 & 0.66 & 0.37 \\
\hline \multirow{4}{*}{\multicolumn{2}{|c|}{ Age Group, Years }} & $18-29$ & 94.00 & 90.70 & 71.40 & 42.30 & 17.60 & 7.70 & 1.60 \\
\hline & & $30-40$ & 86.90 & 81.70 & 68.60 & 42.40 & 20.90 & 6.30 & 1.60 \\
\hline & & $>40$ & 87.00 & 80.40 & 65.20 & 48.90 & 26.10 & 3.30 & 1.10 \\
\hline & & $P$ value & 0.05 & 0.02 & 0.60 & 0.53 & 0.26 & 0.36 & 0.93 \\
\hline \multirow{3}{*}{\multicolumn{2}{|c|}{ Marital Status }} & Not married & 91.50 & 89.30 & 75.40 & 46.40 & 21.40 & 7.10 & 1.30 \\
\hline & & Married & 88.00 & 80.90 & 63.10 & 41.10 & 19.90 & 5.40 & 1.70 \\
\hline & & $P$ value & 0.21 & 0.01 & 0.004 & 0.25 & 0.69 & 0.44 & 0.78 \\
\hline \multirow{6}{*}{\multicolumn{2}{|c|}{ NATIONALITY/RACE }} & Malay & 89.50 & 83.30 & 64.20 & 40.10 & 17.10 & 5.80 & 1.20 \\
\hline & & Chinese & 89.60 & 85.70 & 74.00 & 36.40 & 19.50 & 5.20 & 2.60 \\
\hline & & Indian & 93.20 & 93.20 & 81.80 & 52.30 & 27.30 & 9.10 & 0.00 \\
\hline & & Other_malaysian & 88.60 & 88.60 & 74.30 & 65.70 & 25.70 & 7.70 & 1.90 \\
\hline & & International & 88.50 & 82.70 & 71.20 & 50.00 & 30.80 & 5.70 & 2.90 \\
\hline & & $P$ value & 0.95 & 0.48 & 0.12 & 0.02 & 0.14 & 0.91 & 0.74 \\
\hline \multirow{12}{*}{ Comorbidity } & \multirow{3}{*}{ HTN } & Yes & 86.00 & 74.40 & 58.10 & 37.20 & 23.30 & 7.00 & 2.30 \\
\hline & & No & 90.00 & 86.00 & 70.10 & 44.30 & 20.40 & 6.20 & 1.40 \\
\hline & & $P$ value & 0.41 & 0.04 & 0.11 & 0.37 & 0.66 & 0.83 & 0.64 \\
\hline & \multirow{3}{*}{ DM } & Yes & 91.70 & 87.50 & 66.70 & 50.00 & 20.80 & 0.00 & 0.00 \\
\hline & & No & 89.60 & 84.80 & 69.20 & 43.30 & 20.60 & 6.60 & 1.60 \\
\hline & & $P$ value & 0.74 & 0.72 & 0.80 & 0.52 & 0.98 & 0.19 & 0.53 \\
\hline & \multirow{3}{*}{ Dyslipidemia } & Yes & 97.70 & 90.90 & 72.70 & 47.70 & 29.50 & 13.60 & 2.30 \\
\hline & & No & 88.80 & 84.30 & 68.60 & 43.20 & 19.70 & 5.50 & 1.40 \\
\hline & & $P$ value & 0.07 & 0.25 & 0.60 & 0.57 & 0.12 & 0.03 & 0.66 \\
\hline & \multirow{3}{*}{ CAD } & Yes & 100.00 & 87.50 & 68.80 & 50.00 & 18.80 & 6.20 & 0.00 \\
\hline & & No & 89.30 & 84.90 & 69.00 & 43.40 & 20.70 & 6.20 & 1.60 \\
\hline & & $P$ value & 0.17 & 0.77 & 0.10 & 0.60 & 0.85 & 0.99 & 0.62 \\
\hline \multirow{5}{*}{\multicolumn{2}{|c|}{ Current Position }} & Academicians & 92.50 & 86.20 & 73.80 & 56.20 & 31.20 & 6.20 & 2.50 \\
\hline & & Non academician & 82.40 & 78.00 & 58.20 & 31.90 & 18.70 & 6.60 & 1.10 \\
\hline & & $\begin{array}{l}\text { Undergraduate } \\
\text { student }\end{array}$ & 91.50 & 87.00 & 72.50 & 43.00 & 15.50 & 5.50 & 0.50 \\
\hline & & $\begin{array}{l}\text { Postgraduate } \\
\text { student }\end{array}$ & 90.40 & 86.20 & 68.10 & 45.70 & 24.50 & 7.40 & 3.20 \\
\hline & & $P$ value & 0.08 & 0.23 & 0.07 & 0.02 & 0.02 & 0.93 & 0.28 \\
\hline \multirow{5}{*}{\multicolumn{2}{|c|}{ School }} & Applied arts & 84.40 & 77.00 & 60.70 & 39.30 & 15.60 & 4.90 & 0.00 \\
\hline & & Applied sciences & 93.00 & 89.50 & 71.30 & 42.70 & 23.10 & 8.40 & 1.40 \\
\hline & & Pure arts & 96.10 & 92.20 & 75.30 & 44.20 & 19.50 & 7.80 & 5.20 \\
\hline & & Pure sciences & 87.00 & 82.90 & 70.70 & 48.80 & 23.60 & 4.10 & 0.80 \\
\hline & & $P$ value & 0.021 & 0.008 & 0.11 & 0.51 & 0.37 & 0.42 & 0.03 \\
\hline \multicolumn{2}{|c|}{ Previous Knowledge of HA } & Yes & 90.80 & 86.20 & 70.00 & 44.40 & 21.00 & 6.30 & 1.50 \\
\hline
\end{tabular}




\begin{tabular}{|c|c|c|c|c|c|c|c|c|}
\hline & No & 25.00 & 12.50 & 12.50 & 0.00 & 0.00 & 0.00 & 0.00 \\
\hline & $P$ value & 0.001 & 0.001 & 0.001 & 0.012 & 0.15 & 0.46 & 0.72 \\
\hline \multirow{3}{*}{ Received HA Information } & Yes & 91.50 & 86.50 & 71.10 & 45.40 & 21.80 & 6.60 & 1.30 \\
\hline & No & 81.80 & 78.40 & 60.20 & 36.40 & 15.90 & 4.50 & 2.30 \\
\hline & $P$ value & 0.01 & 0.06 & 0.047 & 0.13 & 0.22 & 0.47 & 0.51 \\
\hline \multirow{3}{*}{ Self-history of HA } & Yes & 100.00 & 92.90 & 78.60 & 42.90 & 21.40 & 14.30 & 0.00 \\
\hline & No & 89.40 & 84.70 & 68.70 & 43.70 & 20.60 & 6.00 & 1.60 \\
\hline & $P$ value & 0.20 & 0.40 & 0.40 & 0.10 & 0.94 & 0.21 & 0.64 \\
\hline \multirow{5}{*}{ Indirect History of HA } & $\begin{array}{l}\text { Immediate family } \\
\text { (1) }\end{array}$ & 93.70 & 90.50 & 80.00 & 56.80 & 25.30 & 9.50 & 1.10 \\
\hline & $\begin{array}{l}\text { Relative, friend or } \\
\text { neighbour ( } 2 \text { ) }\end{array}$ & 90.20 & 85.20 & 67.20 & 41.00 & 18.90 & 4.90 & 0.40 \\
\hline & both $1 \& 2$ & 100.00 & 91.70 & 66.70 & 50.00 & 20.20 & 8.30 & 0.00 \\
\hline & None & 84.20 & 78.90 & 64.00 & 37.70 & 25.00 & 6.10 & 4.40 \\
\hline & $P$ value & 0.08 & 0.11 & 0.07 & 0.03 & 0.60 & 0.47 & 0.03 \\
\hline
\end{tabular}

HTN; hypertention, DM; diabetes mellitus, CAD; coronary artery diseases, HA; heart attack, ${ }^{a}$ includes all correct five symptoms of heart attack (an answer of "Yes") and the trap question (an answer of "No" or "I do not know" to the trap question has been counted). ${ }^{b}$ Includes all correct five symptoms of heart attack (a response of "Yes"), the trap question (a response of "No" or "I do not know" to the trap question has been counted), and the appropriate response at occurrence of symptoms (calling an ambulance).

Self-history of heart attack did not contribute to any significant difference in identifying the individual symptoms. On the contrary, by comparing knowledge of each individual symptom among respondents who never know any person have had heart attack collectively with participants who have indirect history of heart attack (respondents who have history of heart attack in a member of immediate family, those who know any other person diagnosed with heart attack rather than immediate family and those who have both a member of immediate family and know other person exposed to heart attack previously), respondents who have a member of immediate family have had heart attack knew pain or discomfort in the jaw, neck, or back than others $(p=0.03)$ whereas pain or discomfort in the arms or shoulders was more recognized by those who have both a member of immediate family and any other known person have had acute heart attack previously $(p=0.05)$.

Table 2 shows the level of knowledge by the number of identified symptoms and the excellent knowledge. Most $(89.7 \%)$ of the participants knew at least one or more symptom, while only $20.6 \%$ possessed knowledge of all five symptoms. Just $6.20 \%$ of the respondents knew all five symptoms and the trap question (regarding the 5 symptoms of acute heart attack, the answer of "Yes" was defined as being aware of the symptom; but for the trap question however, the answers of "No" and "I do not know," were defined as being aware of the trap question and this definition was also applied to the trap question for excellent knowledge). Generally, 7 (1.50\%) respondents out of 465 had excellent knowledge of heart attack (recognized all 5 symptoms and choose no or I do not know for trap question, choose to call an ambulance as the best option at the occurrence of acute heart attack). In the same context, the excellent knowledge was significantly different in terms of schools and history of heart attack in any known person.

To illustrate this point, respondents who belong to pure arts and those who do not know any person has had a history of heart attack have significantly excellent knowledge ( $p=0.03$ for both) unlike participants from other schools and those who know any person has had a history of heart attack respectively. Higher knowledge also was noticed in women more than men although the significant difference was noticed just in identifying one or more symptoms and two or more symptoms $(92.90 \%$, Vs. $85.80 \%, p=0.01$ and $89.40 \%$ Vs. $79.60 \%, p=0.003$ ) respectively. By comparing the level of knowledge in those who have heard about acute heart attack before and those who have never, we found participants who have heard about heart attack have greater awareness for one or more symptoms $(90.80 \%$ Vs. $25 \%, p=0.001)$, two or more symptoms ( $86.20 \%$ vs $12.50 \%$, $p$-value $=0.001)$, three or more symptoms ( $70 \%$ vs $12.5 \%$, $p=0.001)$, and four or more symptoms $(44.4 \%$ vs $0.00 \%$, $p=0.01$ ).

\section{Factors associated with having knowledge of AHA symptoms identification}

Table 3 indicated the final model of the multiple logistic regressions to determine the factors associated with having knowledge of AHA symptoms identification among USM community. Being a student of school of pure arts, USM was more likely to have an excellent of identifying symptoms of AHA compared to other members of USM community (OR 7.032; 95\% Cl: 0.055-3.851), $\mathrm{p}=0.012$. 
Table 3: Factors associated with having knowledge of AHA symptoms identification

\begin{tabular}{l|c|c|c|}
\hline Parameter & $\begin{array}{c}\text { Adjusted } \\
\text { Odds ratio }\end{array}$ & $\mathbf{9 5 \% ~ C l}$ & P-value \\
\hline Gender & 1.00 & & \\
\hline Male & 0.010 & $0.403-10.927$ & 0.37 \\
\hline Female & &
\end{tabular}

Age Group, Years

18-29

$30-40$

1.00

$>40$

1.077

$0.238-4.868$

0.923

0.672

0.080-5.653

0.715

\section{Marital Status}

Not married

Married

1.243

$0.275-5.618$

0.77

\section{Comorbidity}

HTN

No

Yes

1.651

$0.194-14.040$

0.646

\section{Dyslipidemia}

No

Yes

1.609

0.189-13.674

0.663

\section{Current position}

Academicians

Non academician

1.00

Undergraduate students

0.681

0.081-5.732

0.724

Postgraduate students

0.026-1.816

0.159

School

$0.665-13.753$

0.152

Applied sciences

\section{Pure arts}

Pure sciences

1.00

7.032

\begin{tabular}{|l|l}
$1.541-32.078$ & 0.012
\end{tabular}

0.459

0.055-3.851

0.473

\section{Received HA Information}

Yes

No

$0.110-3.029$

HTN; hypertension, HA; heart attack, aMultiple logistic regression, the model reasonably fits well. Model assumptions are met. There were no interaction and multicollinearity problems

\section{DISCUSSION}

To the best of our knowledge, this is the first study conducted in Malaysia to assess the awareness of symptoms of acute heart attack and the response to the symptoms, in a community sample. In the present study, most respondents had previously heard about heart attack (98.3\%). The overall level of knowledge about each individual symptom, as well as about the collective symptoms of acute heart attack was higher than that reported in some other countries ${ }^{4,16-19}$. However, the level of awareness was lower than that in countries like the USA and Canada ${ }^{20,21}$. In addition, the level of awareness about the importance of calling for an ambulance was much lower than that seen in most surveys in Nepal $(77.6 \%)^{18}$ and Korea $(67 \%)^{22}$, but was higher than that seen in Nigeria $(6.7 \%)^{19}$. A similar level of awareness as seen in our study about the importance of calling for an ambulance in the case of an acute heart attack was reported in a survey among the Aydin population in Turkey $(22.2 \%)^{17}$. In the present study, chest pain was the most commonly identified symptom of heart attack, which is similar to that reported in previous studies $^{22},{ }^{23}$ but was not consistent with the findings of studies conducted in Turkey ${ }^{17}$ and Nepal ${ }^{18}$.

The least commonly recognised symptom was sudden pain or discomfort in the jaw, neck, or back; this was consistent with the findings of surveys conducted in Nigeria ${ }^{19}$ and in the $U^{20}$ but was inconsistent with the findings of some other studies ${ }^{4,16}$. Difficulty in breathing ranked as the second most identified symptom of heart attack in participants from the USM community and this is similar to the findings of studies conducted in Korea and Nigeria ${ }^{18},{ }^{19}$. About $45.2 \%$ of the participants identified sudden pain or discomfort in the arms or shoulders; however, in the USA about $85.6 \%$ of participants identified pain in the arms and shoulders.

International students appear to have better knowledge than the USM locals, about the symptoms of heart attack. This could be owing to the paucity of data about the lack of knowledge of acute heart attack in Malaysia. Indians also showed insignificantly higher knowledge about the symptoms of heart attack than other locals. However, regarding excellent knowledge there is no any Indian individual who has excellent knowledge. People who had heard about heart attack had better knowledge than those who had never heard about the disease, and the differences were significant for the four symptoms; this is consistent with that seen in previous studies ${ }^{4,21}$.

The availability of information related to heart attack was found to have a positive impact in identifying all the symptoms ${ }^{24}$; however, the impact was significant only in identifying one or more symptoms and three or more symptoms. A personal history of acute heart attack in the past made a slight impact in identifying all symptoms. It is important to mention here that the lack of significant difference in awareness based on pre-existing cardiac disease and a personal history of heart attack seen in the study, might be because few participants who have these factors in the setting of study where the frequency of participants with those factors did not reach to the quarter of sample size for each individual factor. Participants having an immediate family member with a history of heart attack did not have significantly more knowledge in identifying all the symptoms or about the importance of calling for an ambulance. Regarding excellent knowledge, those who do not have the indirect history of acute heart attack were significantly more knowledgeable. Kim et al in their study reported that a history of heart attack among respondents or in an immediate family member, relatives, acquaintances, or neighbours increased the level of 
awareness; however, in our study an immediate family member or any other known person was not included in the comparison $^{23}$. Multiple logistic regression analysis indicated that students of the school of pure arts at USM were seven times more likely to have an excellent knowledge in identifying symptoms of AHA compared to other members of the USM community.

Overall, the level of awareness in identifying symptoms of AHA among the USM community in this study was low, compared to that seen in some other countries including the US. This could be because medical care for this condition receives a high priority in those countries. The high morbidity and mortality rate associated with CAD in Malaysia, coupled with the findings of this study suggests the need for further studies to investigate the disease burden, to plan for targeted interventions ${ }^{22-24}$.

Our study suffered from several limitations. First, this study demonstrated the general perspective of USM community, therefore, the findings cannot be generalised to the large Malaysian population. Second, few numbers of participants who have risk factors for heart attack in the setting of study might be the reason for inability to determine so much association between each individual risk factor and level of knowledge. Finally, non-probability sampling was used to recruit the participants which may be related to selection bias. Further research should be carried out with a larger sample size and among a larger population using a representative sample to confirm the findings of this study and bridge the limitations identified.

In conclusion, lack of knowledge and awareness was observed among USM community, the poor knowledge of heart attack leads to delay of patient arrival to the hospital, hence life-threating outcomes of disease. The current study demonstrates the need to enhance people's knowledge about heart attack by establishing educational programmes and activities. Although educational activities are required to be forward for whole USM community members, the priority of such educational endeavours should be given for males, older people, and married, people who have never heard about heart attack, undergraduate students, USM staff, and those who belong to schools rather than schools defined by pure arts schools.

\section{DECLARATIONS}

\section{Acknowledgements}

The authors would like to thank Universiti Sains Malaysia and all participants in this study.

\section{Conflicts of Interest}

Authors declare that no conflict of interest in doing this research.

\section{Contribution of authors}

We declare that this work was done by the authors named in this article and all liabilities pertaining to claims relating to the content of this article will be borne by the authors.
Study conception and design: Omar Y.A. Al-Shargi, Amer Hayat and Sultan A.M. Saghir, Data collection: Omar Y.A. AlShargi and Amer Hayat, Data analysis and interpretation: Omar Y.A. AL-Shargi, Sultan A.M. Saghir, Omar S.A. Alsalahi and Ayman M. Mahmoud, Drafting of the article: Omar Y.A. AL-Shargi, Sultan A.M. Saghir, Abdullah S. AL-Wajeeh, Nader AL-Balagi and Wesam AL-Amarat, Critical revision of the article: Sultan A.M. Saghir and Ayman M. Mahmoud

\section{REFERENCES}

1. Bolooki, HM, and Arman A. "Acute myocardial infarction." Disease Manag Proj (2010).

2. Scheen AJ. From atherosclerosis to atherothrombosis: from a silent chronic pathology to an acute critical event. Rev Med Liege 73, 2018, 224-8.

3. Nascimento, BR., Brant, LCC., Marino, BC., Passaglia, LG \& Ribeiro, ALP. Implementing myocardial infarction systems of care in low/middle-income countries. Heart 105, 2019, 20-26.

4. Kim HS, Lee H, Kim K, Park HK, Park KS, Kang GW, Shin HY, Kim RB, Oh GJ, Seo JH, Lee YH. The general public's awareness of early symptoms of and emergency responses to acute myocardial infarction and related factors in South Korea: a national public telephone survey. J Epidemiol 5, 2016, JE20150074.

5. McNamara RL, Wang $Y$, Herrin J, Curtis JP, Bradley EH, Magid DJ, Peterson ED, Blaney $M$, Frederick PD, Krumholz HM. Effect of door-to-balloon time on mortality in patients with ST-segment elevation myocardial infarction. J Am Coll Cardiol 6,47(11), 2006, 2180-6.

6. Boersma E, Maas AC, Deckers JW, Simoons ML. Early thrombolytic treatment in acute myocardial infarction: reappraisal of the golden hour. The Lancet 21,348(9030), 1996, 771-5.

7. Simoons $M L$, Serruys $P W$, van den Brand $M$, Verheugt FW, Krauss XH, Remme WJ, Bär F, de Zwaan C, van der Laarse A, Vermeer F, et al.. Early thrombolysis in acute myocardial infarction: limitation of infarct size and improved survival. J Am Coll Cardiol 1,7(4), 1986, 71728.

8. Kaul P, Armstrong PW, Sookram S, Leung BK, Brass N, Welsh RC. Temporal trends in patient and treatment delay among men and women presenting with STelevation myocardial infarction. Am Heart J 1,161(1), 2011, 91-7.

9. Ängerud $\mathrm{KH}$, Thylén I, Lawesson SS, Eliasson $\mathrm{M}$, Näslund U, Brulin C, SymTime Study Group. Symptoms and delay times during myocardial infarction in 694 patients with and without diabetes, an explorative cross-sectional study. BMC Cardiovasc Disord 1,16(1), 2016, 108.

10. Ängerud $\mathrm{KH}$, Brulin $\mathrm{C}$, Eliasson $\mathrm{M}$, Näslund $\mathrm{U}$, Hörnsten $\AA$. The process of care-seeking for myocardial infarction 
among patients with diabetes. J Cardiovasc Nurs 30(5), 2015, E1.

11. Isaksson RM, Brulin C, Eliasson M, Näslund U, Zingmark K. Prehospital experiences of older men with a first myocardial infarction: a qualitative analysis within the Northern Sweden MONICA Study. Scand J Caring Sci 25(4), 2011, 787-97.

12. Khraim FM, Carey MG. Predictors of pre-hospital delay among patients with acute myocardial infarction. Patient Educ Couns 1,75(2), 2009, 155-61.

13. Saczynski JS, Yarzebski J, Lessard D, Spencer FA, Gurwitz JH, Gore JM, Goldberg RJ. Trends in prehospital delay in patients with acute myocardial infarction (from the Worcester Heart Attack Study). Am J Cardiol 15,102(12), 2008, 1589-94.

14. O'Donnell S, Condell S, Begley C, Fitzgerald T. Prehospital care pathway delays: gender and myocardial infarction. J Adv Nurs 53(3), 2006, 268-76.

15. McGinn AP, Rosamond WD, Goff Jr DC, Taylor HA, Miles JS, Chambless L. Trends in prehospital delay time and use of emergency medical services for acute myocardial infarction: experience in 4 US communities from 1987-2000. Am Heart J 1,150(3), 2005, 392-400.

16. Whitaker S, Baldwin T, Tahir M, Choudhry O, Senior A, Greenfield S. Public knowledge of the symptoms of myocardial infarction: a street survey in Birmingham, England. Fam Pract 1,29(2), 2012, 168-73.

17. Memiş S, Evci ED, Ergin F, Beşer E. A population-based study on awareness of heart attack in Aydın cityTurkey. Anatol. J Cardiol 2009, 1,9(4).
18. Limbu YR, Malla R, Regmi SR, Dahal R, Nakarmi HL, Yonzan G, Gartaula RP. Public knowledge of heart attack in a Nepalese population survey. Heart Lung 1,35(3), 2006, 164-9.

19. Kolo PM, Ogunmodede JA, Sanya EO, Bello HS, Ghadamosi MS, Dele-Ojo BF, Katibi IA, Omotoso AB. Public knowledge of heart attack symptoms and prevalence of self-reported cardiovascular risk factors in Ilorin, Nigeria. Nig J Cardiol 1,12(2), 2015, 95.

20. Greenlund KJ, Keenan NL, Giles WH, Zheng ZJ, Neff LJ, Croft JB, Mensah GA. Public recognition of major signs and symptoms of heart attack: seventeen states and the US Virgin Islands, 2001. Am Heart J 1,147(6), 2004, 1010-6.

21. Ratner PA, Johnson JL, Mackay M, Tu AW, Hossain S. Knowledge of "heart attack" symptoms in a Canadian urban community. Clin Med Cardiol 2008, 2, CMCS709.

22. Kim EM, Hwang SY, Kim AL. Knowledge of stroke and heart attack symptoms and risk factors among rural elderly people: A questionnaire survey. Korean Circ J 1,41(5), 2011, 259-64.

23. Noureddine S, Froelicher ES, Sibai AM, Dakik H. Response to a cardiac event in relation to cardiac knowledge and risk perception in a Lebanese sample: a cross sectional survey. Int J Nurs Stud 1,47(3), 2010, 332-41.

24. Hertz JT, Madut DB, Tesha RA, William G, Simmons RA, Galson SW, Sakita FM, Maro VP, Bloomfield GS, Crump JA, Rubach MP. Knowledge of myocardial infarction symptoms and perceptions of self-risk in Tanzania. Am Heart J 1,210, 2019, 69-74.

\section{Source of Support: None declared.}

Conflict of Interest: None declared.

For any question relates to this article, please reach us at: editor@globalresearchonline.net New manuscripts for publication can be submitted at: submit@globalresearchonline.net and submit_ijpsrr@rediffmail.com 